\title{
Warren Thomas Blume, OC, MD, FRCPC
}

\author{
G. Bryan Young, Richard S. McLachlan
}

Keywords: EEG, Epilepsy

doi:10.1017/cjn.2021.230

Can J Neurol Sci. 2022; 49: 820

With great sadness we mark the passing of Dr Blume on September 13, 2021. A graduate of Princeton and McGill Universities, he did post-graduate training at Mayo Clinic, Montreal Children's Hospital and Hôpital Port Royal in Paris. He joined the newly formed Department of Clinical Neurological Sciences at Western University, London, Ontario, in 1972, where he served on faculty until his retirement in 2007. He continued to contribute as an emeritus professor until near the time of his passing.

Professor Blume made important contributions to epileptology and electroencephalography (EEG), including eight textbooks and numerous articles in peer-reviewed journals. He cofounded the Canadian League Against Epilepsy and, with Dr John Girvin, founded the first comprehensive epilepsy program in Ontario, the second such program in Canada. He also served as President of the Canadian League Against Epilepsy, the Canadian Association of Child Neurology, The Canadian Board of EEG Technologists, The Canadian Association of Clinical Neurophysiologists, and the American Clinical Neurophysiology Society and on numerous committees and task forces for the International League Against Epilepsy, The American Epilepsy Society, and the American Clinical Neurophysiology Society. For these contributions, he received numerous awards, including seven distinguished lectureships, the Penfield Award (Canadian
League Against Epilepsy), the Commemorative Medal for the Queen's Golden Jubilee (Canadian Medical Association), the HOPE Award (London, Canada), The Herbert Jasper Award (American Clinical Neurophysiology Society), the Kiffin Penry Award (American Epilepsy Society), the Ambassador for Epilepsy Award (International League Against Epilepsy), and the Order of Canada.

Warren, or WT as he was sometimes known, was a passionate and gifted teacher who inspired many neurology residents to pursue the disciplines of EEG and Epileptology. Numerous epilepsy fellows who trained with him embarked on successful academic careers often including the establishment of new epilepsy programs not only in Canada but throughout the world. He was always patient, supportive, kind, and of good humor, while striving for quality and precision. His EEG reading sessions and epilepsy teaching rounds were exemplary reflecting his detailed and accurate recollection of the medical literature that always paid homage to leaders in the clinical as well as basic sciences.

His legacy will live on in those he taught and the students of his mentees as well as in his written works.

\section{Disclosures}

No disclosures for either GBY or RSM. 